\title{
Biostatistics: road less travelled
}

\section{Darshankumar K. Dharaiya*}

Department of Psychiatry, Government Medical College, Surat, Gujarat, India

Received: 24 October 2020

Revised: 10 December 2020

Accepted: 17 December 2020

\section{*Correspondence:}

Dr. Darshankumar K. Dharaiya,

E-mail: dharaiya.darshan@gmail.com

Copyright: ( ) the author(s), publisher and licensee Medip Academy. This is an open-access article distributed under the terms of the Creative Commons Attribution Non-Commercial License, which permits unrestricted non-commercial use, distribution, and reproduction in any medium, provided the original work is properly cited.

\begin{abstract}
Initially developed as a branch of mathematics, biostatistics has evolved to take important position in the field biomedical research including medicine. Currently biostatistics has been used in almost all areas of biomedical research as well as treatment and planning for heath related programmes and resource distribution. Despite being of paramount importance, biostatistics is the field which is mostly neglected by students and professionals due to various reason which can have long-term impact on education, research, treatment and health programs and policy making as well. Very few institutes are providing training in the field of biostatics and less and less scholars are taking interest in that training. Researchers have come up with newer approaches to teach the subject and they have shown encouraging results, but still its long way to statistical literacy in the medical field.
\end{abstract}

Keywords: Biostatistics, Statistical error, Education of biostatistics

\section{INTRODUCTION AND EVOLUTION OF BIOSTATISTICS}

When you can measure what you are speaking about and express it in numbers, you know something about it but when you cannot measure, when you cannot express it in numbers, your knowledge is of a meager and unsatisfactory kind - Lord Kelvin. ${ }^{1}$

Biostatistics is a branch of statistics (which is in turn branch of mathematics) which is concerned with the analysis of data gathered from biological sciences and related fields like medicine, psychology, epidemiological studies, drug trials, zoology, botany, genetics and marine research to name a few. biostatistics is concerned with hypothesis formation, collection of data from biological experiments, analysis and interpretation of data, description of data and forming conclusion based on the result. With the evolution of fields of medicine and as the need arises biostatistics has evolved into statistics has an interesting history. ${ }^{2,3}$ An endless list of people who have contributed to the current form of biostatistics as it is can be prepared, starting from Abraham de moivre, Quetelet,
Thomas bayes, Pierre-Simon Laplace, Carl Fredrich gauss, john snow, Florence nightingale, Sir Francis Galton, Karl Pearson, William S. Gosset, and in recent times Ronald Fisher, John W. In India prof. P. C. Mahalanobis $^{4}$ and prof. P. V. Sukhatme ${ }^{5}$ were pioneers in statistics and biostatistics.

\section{BIOSTATISTICS AND MEDICINE}

Every medical student asks a question that I am going to be a doctor, not a mathematician or statistician then why I should study this subject? In Indian medical schools, biostatistics comes as part of preventive and social medicine from 2 nd year onwards and stays with a doctor for probably the rest of his life in one or another form, whether he knows or not. As an undergraduate, postgraduate, as a teacher, as a guide, as a researcher, or as a professional who is looking at an article published in a medical journal you will come across biostatistics. As undergraduate you are expected to pass in the subject. As postgraduate you will need biostatistics while preparing for papers, poster or thesis and for publication of your research work. If you are in a teaching institute and you 
think of carrying out any research, you will need to start from scratch, like sample size calculation, hypothesis formation, type of data which will be collected, how data will be analysed, what result can be expected from the research and after all these, when you try to publish a result of your study in any journal, they will also ask you to provide correct statistical data from the study and in corrected format. So again, we crossed ways with biostatistics. As a guide, as a mentor, and a part of the scientific committee, you are expected to guide students in their research work, review their protocol that correct scientific methods are applied. As a medical professional or student whenever you read any journal or article and may just skip what you may perceive to be statistical jargon because of your own limits of knowledge in the field of biostatistics. But without knowing whether the study that carried out was done properly or not, data was analysed property or not, how can you decide whether to accept or discard the results of the given study? In our day-to-day life, as a medical practitioner or as an ordinary living fellow, when we read about some scientific research pertaining to the medical field which is published in the newspaper, how can we be sure about what to take out of the article? To rely on it or not?

In the ever-evolving field of evidence-based medicine, all the recommendations are done based on systemic review and meta-analysis. But as it is known as garbage in garbage out, what goes into such meta-analysis will come out and ultimately will have an effect on patient care. Such meta-analysis is also not without limitation from a statistical point. It is important to use statistics early in any research design, beginning from hypothesis formation, sample size calculation, and all the way until the publication of properly written statistical data in the publication. Because errors in any stage of the research will lead to a waste of human resources and raise ethical questions. Also, poorly carried out research will adversely affect the recipients of the result in the future.

\section{KNOWLEDGE PROFESSIONALS \\ AMONG \\ MEDICAL}

Despite having so much effect of biostatistics on our personal, professional, and academic life, biostatistics is a field that is more or less ignored by students and teachers alike. Along with epidemiology, biostatistics is a field that is ignored by the majority of medical students during the study and they come to appreciate it fully only when they are qualified doctors. ${ }^{6}$ Residents from the various branch of medicine have shown inadequate knowledge and practice skills regarding biostatistics, like postgraduates as a whole, orthopedics, pharmacology, homeopathy, dental and faculty as well. ${ }^{7-16}$ despite having understanding of importance of biostatistics in the field, there was low level of perceived knowledge regarding biostatistics among clinicians. ${ }^{17}$

\section{STATISTICAL ERRORS IN MEDICAL JOURNALS}

"There are three kinds of lies: lies, damned lies, and statistics."- unknown?

Just like any other science, biostatistics is also not errorfree. Errors during statistical procedures are very common and at times very serious that sometimes whole research and its conclusions can be put in questions when proper statistical methods are not applied or poor statistical methods are applied. Knowingly or unknowingly, or because of other gains, statistical errors make their ways in the medical research process and ultimately to publications at times. Although any research or study is approved by the relevant ethics committee and scientific review committee, when the manuscript is sent for publication, the editorial board reviews the manuscript for statistical errors other ethical issues. An error can occur at any stage, starting from the research question, research protocol, hypothesis formation, sample size calculation, data collection, data analysis, data interpretation, and in the end data presentation. ${ }^{18}$ In the initial phase, epidemiological methods may have the upper hand but as the study moves furthermore and more statistical methods come into play and in the end, its harmonies interplay between epidemiological methods and statistical methods which generates scientifically valid results. But despite all the effort because of lacunas in knowledge at the level of the researcher, scientific review, data analyst, author or editor and reviewer of the respective journal, articles with varying degree of statistical errors makes their way in medical journals. And this problem is not of recent origin.in 1966, probably the first paper was published looking at the statistical evaluation of manuscripts published in medical journals. ${ }^{19}$ but after that and in current times, statistical errors in medical journals are no less than before. ${ }^{20-25}$

\section{BIOSTATITSCS AND MEDICAL EDUCATION}

Looking at the importance of biostatistics in the field of health, in the $48^{\text {th }}$ world health assembly, who urged all member countries to educate, reorient, and to contribute towards health for all by helping in research and other relevant clinical and academic activities. ${ }^{26}$ But in the majority of medical colleges, biostatistics is not being taught as a separate discipline but it constitutes only a very small portion of the curriculum and most of the time which is taught by instructors who are not trained biostatisticians. Only about 19 institutions in India are offering various courses in biostatistics/medical statistics/health statistics/biometry. ${ }^{3}$ to improve the research skills of Indian medical postgraduates and teachers in medical institutions, the board of governors (BOG) in supersession of the medical council of India (MCI) has mandated a uniform research methodology course. ${ }^{27}$ The course is mandatory for all 1 st-year postgraduate students and for all medical faculty who will be joining or getting promoted to grade above the assistant professor. ${ }^{28}$ This online course, "basic course in 
biomedical research", which is offered by ICMR-national institute of epidemiology (ICMR-NIE), Chennai. In the current time of information and technology, where everything is just a click away, it has provided with opportunities to learn biostatistics online as MS office excel, graph pad prism, SPSS, NCSS, Instant, Dataplot, Sigmastat, Graph pad Instat, SYSSTAT, Genstat, MINITAB, SAS, STATA, and sigma graph pad. Free website for statistical software is www.statistics.com, http://biostat.mc.vanderbilt.edu/wiki/main/powersamplesi ze. A wide range of books to study biostatistics are available. ${ }^{29,30}$ Online course are also available. ${ }^{31,32}$ There have been many articles published in journals from time to time giving a glimpse into the field and trying to explain many concepts of biostatistics. ${ }^{33-35}$ looking at inadequate knowledge among students, it is necessary to start a separate training programmer for biostatistics in the curriculum. ${ }^{36}$ there have been various approaches for education about biostatistics to students like designing new curriculum, flipped classroom model, short biostatistics course to name a few. ${ }^{37-39}$

\section{CONCLUSION}

Considering the importance of biostatistics in the medical field as a whole, and looking at the current scenario regarding biostatistics' knowledge and perception among students and professionals, and its impact on medical research and publication, it is need of the hour to take steps regarding education about biostatistics and all the level in medical education, be it undergraduate, postgraduate or consultant. Appropriate steps and newer teaching methods can be employed for the same.

Funding: No funding sources

Conflict of interest: None declared

Ethical approval: Not required

\section{REFERENCES}

1. Editorial. Why statistics? Indian J Psychiatry. 1962;IV(4):175-6.

2. Matthews JR. History of biostatistics. Med Writ. 2016;25(3):8-11.

3. Singh R, Zodpey SP, Sharma K, Bangdiwala SI, Ughade S. Landscaping biostatistics education in India. Indian J Public Health. 2012;56(4):273-80.

4. Rao TJ. Official statistics in India: The past and the present. J Off Stat. 2010;26(2):215-31.

5. Sukhatme S. Pandurang V. Sukhatme 1911-1997. J Stat Plan Inference. 2002;102(1):3-24.

6. Mostert P. Changing approaches and perceptions: biostatistics and its role in teaching the stellenbosch doctor. Published online 2006:1-6.

7. Harshe D, Abraham D. A study of attitudes of teaching faculty and postgraduate residents at a tertiary care teaching hospital toward biostatistics. Muller J Med Sci Res. 2017;8(1)10-4.

8. Shafi MS, Faisal T, Naseem S, Javed S. Postgraduate medical trainees' understanding of biostatistics: A pre- and post-research methodology workshop experience. J Coll Physicians Surg Pakistan. 2018;28(3):196-200.

9. Araoye I, He JK, Gilchrist S, Stubbs T, McGwin G, Ponce BA. A National Survey of Orthopaedic Residents Identifies Deficiencies in the Understanding of Medical Statistics. J Bone Jt SurgAm. 2020;102(5):e19.

10. Jiroutek MR, Kim MJ, Hayat MJ, Taylor MN, Schwartz TA. A cross-sectional assessment of statistical knowledge among pharmacy faculty. Curr Pharm Teach Learn. 2019;11(8):793-801.

11. Saha S, Koley M, Mondal R, Kundu M, Ghosh A, Ghosh $\mathrm{S}$ et al. Understanding of biostatistics among the homeopathic fresh graduates and post-graduate trainees in West Bengal, India. Int J High Dilution Res. 2014;13(48):172-81.

12. Kumar L, Shahnawaz K, Choudhary SK, Sarker G, Barman SK, Singh jitendra B. Attitudes Toward Biostatistics Among Post-Graduate Medical Students in Kishanganj, Bihar. J Evol Med Dent Sci. 2014;03(03):758-61.

13. Batra M, Gupta M, Dany SS, Rajput P. Perception of Dental Professionals towards Biostatistics. Int Sch Res Not. 2014;2014:1-6.

14. Polychronopoulou A, Eliades T, Taoufik K, Papadopoulos MA, Athanasiou AE. Knowledge of European orthodontic postgraduate students on biostatistics. Eur J Orthod. 2011;33(4):434-40.

15. Akinsola O, Ibikunle A, James O, Adeyemo W. Understanding biostatistics: A study of Nigerian dental resident doctors. Niger J Exp Clin Biosci. 2014;2(2):100-4.

16. Ashwin CS, Noura MAR, Sara AA. Dental professionals attitude towards biostatistics. J Dent Oral Hyg. 2015;7(7):113-8.

17. West CP, Ficalora RD. Clinician attitudes toward biostatistics. Mayo Clin Proc. 2007;82(8):939-43.

18. Strasak AM, Zaman Q, Pfeiffer KP, Göbel G, Ulmer H. Statistical errors in medical research - A review of common pitfalls. Swiss Med Wkly. 2007;137(34):44-9.

19. Schor S KI. Statistical evaluation of medical journal manuscripts. J Am Med Assn. 1966;195:1123-8.

20. Leaphart DM, Cronley AC, Brothers TE. Errors in Reporting Significant Figures in Surgical and Medical Journals in 2017. J Surg Res. 2019;243.

21. Diong J, Butler AA, Gandevia SC, Héroux ME. Poor statistical reporting, inadequate data presentation and spin persist despite editorial advice. PLoS One. 2018;13(8):e0202121.

22. Lang TA, Altman DG. Statistical analyses and methods in the published literature: The SAMPL guidelines. Med Writ. 2016;25(3):31-6.

23. Low ZX, Yeo KA, Sharma VK, Leung GK, McIntyre RS, Guerrero A et al. Prevalence of burnout in medical and surgical residents: A meta-analysis. Int $\mathbf{J}$ Environ Res Public Health. 2019;16(9):1-22.

24. Bahar B, Pambuccian SE, Barkan GA, Akdaş Y. The use and misuse of statistical methods in 
cytopathology studies: Review of 6 journals. Lab Med. 2019;50(1):8-15.

25. Kim JS, Kim DK, Hong SJ. Assessment of errors and misused statistics in dental research. Int Dent $\mathrm{J}$. 2011;61(3):163-7.

26. World Health Organization (WHO). Forty-Eight World Health Assembly. Resolution 48.8. Reorientation of medical education and medical practice for health for all. 1995;4:1-2.

27. Board of Governors in Super-session of Medical Council of India. Postgraduate Medical Education (Amendment) Regulations, 2019. 2019;2019(D):4-6.

28. Authority PBY, Delhi NEW.AIIMS Annual Convocation, 2020. 2020;2020(D).

29. Banerjee B. Mahajan's Methods in Biostatistics for Medical Students and Research Workers. Ninth. Jaypee brothers medical publishers pvt. ltd. 2018.

30. Twomey P. Oxford Handbook of Medical Statistics: Oxford Medical Handbooks. Ann Clin Biochem Int J Lab Med. 2012;49(3).

31. Fundamentals of Biostatistics, Harvard University. Available from: https:/onlinelearning.harvard.edu/course/fundamentalsbiostatistics?delta=0. Accessed October 24, 2020.

32. Biostatistics Courses Coursera. Available from: https://www.coursera.org/search?query=biostatistics $\&=$. Accessed October 24, 2020.

33. Labani S, Asthana S. Basics of biostatistics for understanding research findings. MAMC J Med Sci. 2015;1(3):1-7

34. Andrade C. Sample size and its importance in research. Indian J Psychol Med. 2020;42(1):102-3.

35. Andrade C. Understanding the Difference Between Standard Deviation and Standard Error of the Mean, and Knowing When to Use Which. Indian J Psychol Med. 2020;42(4):409-10.

36. Ille TM, Muthukrishnan R, Ille ME. Integrating medical biostatistics into postgraduate medical curriculum. Natl Med J India. 2017;30(4):212-4.

37. Arias A, Peters OA, Broyles IL. New curricular design in biostatistics to prepare residents for an evidence-based practice and lifelong learning education: a pilot approach. Int Endod J. 2017;50(10):999-10.

38. Mclaughlin JE, Kang I. A flipped classroom model for a biostatistics short course. Stat Educ Res J. 2017;16(2):441-53.

39. Chima SC, Nkwanyana NM, Esterhuizen TM. Impact of a short biostatistics course on knowledge and performance of postgraduate scholars: Implications for training of African doctors and biomedical researchers. Niger $\mathbf{J}$ Clin Pract. 2015;18(7):62-70.

Cite this article as: Dharaiya DK. Biostatistics: road less travelled. Int J Community Med Public Health 2021;8:975-8. 